\title{
REMOTE COLLABORATION AND INNOVATIVE PERFORMANCE: THE MODERATING ROLE OF R\&D INTENSITY
}

\author{
Luca Berchicci ${ }^{1}$ \\ Jeroen P.J. de Jong ${ }^{1, *}$ \\ Mark Freel ${ }^{2,3}$
}

* Corresponding author. Burgemeester Oudlaan 50, 3062 PA Rotterdam, The Netherlands. Phone +31

(0)10 4082764 E-mail: jjong@ @rsm.nl.

${ }^{1}$ RSM Erasmus University, Rotterdam, The Netherlands

${ }^{2}$ Telfer School of Management, University of Ottawa, Canada

${ }^{3}$ IEED Lancaster University Management School, Lancaster University, UK 


\section{Abstract}

Collaboration with geographically distant partners may enhance a firm's innovative performance. In practice, however, this may be complicated as personal contacts are more limited so that effective search and transfer of remote partners' tacit knowledge is frustrated. We tested the potential moderating role of R\&D intensity which, by indicating technology-oriented absorptive capacity, may mitigate the problems associated with remote collaboration. Drawing on survey data of 248 high-tech small firms we find that remote collaboration is positively related with innovation performance, but at low $\mathrm{R} \& \mathrm{D}$ intensity the relationship vanishes.

\section{Keywords}

Innovation collaboration, new product revenues, geographical distance, absorptive capacity, high-tech small firms, tacit knowledge.

\section{JEL codes}

O32 - Management of Technological Innovation and R\&D

O18 - Regional, Urban, and Rural Analyses; Transportation 


\section{REMOTE COLLABORATION AND INNOVATIVE PERFORMANCE: THE MODERATING ROLE OF R\&D INTENSITY}

\section{INTRODUCTION}

One of the most prominent findings in innovation studies relates external collaboration to innovation performance. Both the likelihood and the novelty of innovation appear to increase when external partners are involved (Tomlinson, 2010). Studies of innovation collaboration also frequently document a spatial dimension (Huggins and Johnston, 2010). Specifically, scholars have shown empirically that geographically distant partners are more likely to be sources of heterogeneous and diverse knowledge which can further enhance innovation performance (e.g., Grotz and Braun, 1997; Freel, 2003; Tödtling, Lehner and Trippl, 2006).

However, collaboration at a distance brings additional challenges to effectively search and benefit from external knowledge (Hoekman, Frenken and Tijssen, 2010). At great geographical distance opportunities for frequent interpersonal contacts are limited, making it more difficult to find good collaboration partners and to effectively transfer and exploit their knowledge. These challenges help explain why knowledge spillovers are initially mostly local and why knowledge diffusion across regions progresses slowly (Jaffe, Trajtenberg and Henderson, 1993). Past work suggests that such problems become more acute when partners are hundreds of kilometers away (Botazzi and Peri, 2003; Greunz, 2005), making face-to-face meetings more costly and less common.

In this paper we are concerned with how firms may overcome these identification and communication challenges in order to benefit from collaborations with 
geographically distant partners. We suggest that intense engagement in R\&D mitigates the problems associated with remoteness. Our main hypothesis is that R\&D intensity positively moderates the relationship between remote collaboration and firms' innovative performance. R\&D intensity indicates better technology-focused absorptive capacity which, in turn, is likely to enable better search, transfer and exploitation of knowledge. As we will argue later, this is especially helpful in the case of remote collaborations where the extent or deployment of common knowledge transfer mechanisms (e.g., personal social networking, labor mobility) is limited.

Past research has focused on firms' propensity to engage in remote collaboration (Drejer and Vinding, 2007; de Jong and Freel, 2010) and noted a direct association between distant collaboration and innovative performance (e.g., Grotz and Braun, 1997). To our knowledge no research has explored contingency factors: under what circumstances firms are more or less likely to benefit from geographically distant partners. In doing so, we also contribute to the growing line of research on how R\&D moderates the relationship between external knowledge sourcing and innovation performance. Recent studies have found that measures of R\&D intensity positively moderate the effectiveness of the volume of external knowledge sourcing (Escribano, Fosfuri and Tribo, 2009), ambidextrous technology sourcing (Rothaermel and Alexandre, 2009), innovation collaboration with specific types of partners, including suppliers, clients, competitors and universities (Tsai, 2009), and the incidence and success of R\&D offshoring (Bertrand and Mol, 2013). We here take a next step by investigating the moderating role of R\&D intensity on innovation performance in the case of collaboration at a distance, that is, remote collaborations. This allows us to make an empirical 
contribution to debates on the merits of extended innovation networks by highlighting the role of an important contingency and to theoretical discussions on use of enhanced absorptive capacity as a means to overcome problems with geographical distance.

We first discuss the theory underpinning the development of our hypotheses. Next, we present and analyze data from 248 high-tech small firms. We find that among high-tech small firms remote collaboration is positively related with innovation performance, but at low R\&D-intensity the relationship is not significant.

\section{THEORY AND HYPOTHESES}

In this section, we first explain why collaboration at greater geographical distance is expected to correlate with innovative performance. Following this, we develop the interaction hypothesis that underlies our anticipated contingency.

\section{Remote collaboration}

The past decades have witnessed growing evidence that the organizational boundaries of innovation are shifting from an internal $\mathrm{R} \& \mathrm{D}$ department to a reality where corporate partnering, collaboration and external sourcing are widespread. A substantial number of studies have testified that innovation collaboration is extensive and increasing (e.g., van der Vrande, de Jong, Vanhaverbeke and de Rochemont, 2009); and this is particularly so for technology-intensive firms (e.g., Bayona, Garcia-Marca and Huerta, 2001; Miotti and Sachwald, 2003). This trend is also evident in Chesbrough's (2003) Open Innovation model, which counsels organizations that many of the resources required to innovate reside outside of the firm and that accessing these resources is an important step in 
successful innovation. ${ }^{1}$ Indeed, the evidence that innovation collaboration is positively associated with firms' innovation performance is longstanding (Oerlemans, Meeus and Boekema, 1998; Freel, 2003; Fukugawa, 2006; Nieto and Santamaria, 2007).

A number of factors underlie this trend. However, fundamental to the process is the recognition that innovations require diverse inputs (Kogut and Zander, 1992; Bertrand and Mol, 2013). Of course, diversity may exist within firms. But it is more likely to be found across organizational boundaries. To the extent that organizational members share experiences and backgrounds, organizations develop collective mental models and interpretative schemes that shape decision-making (Lam, 2006). This is sometimes termed 'collective cognition' and is likely to hinder innovation (Mezias, Grinyer and Guth, 2001). Following this, other organizations (customers, suppliers, universities, and so on) are increasingly viewed as critical sources of diverse inputs and cognitions. Here, the friction between different mental models, or ways of doing things, is thought to result in 'creative abrasion' (Leonard and Straus, 1997) and increased innovation - over-andabove that which results from simply pooling resources.

In the present analysis, we go further and argue that cognitive proximity diminishes with geographic distance. That is, whilst 'other' organizations are likely to be the source of diverse inputs, those located remotely are likely to be even more distant when it comes to cognition. Underpinning this position is a belief that the cognitive distance between firms is determined by a variety of factors, but that primary amongst these factors is firms' location (Bertrand and Mol, 2013). Of course, sectoral considerations will influence cognitive proximity, such that firms within the same

\footnotetext{
${ }^{1}$ In addition, Open Innovation is also concerned with the notion that there may be other ways to commercialize innovations beyond firms taking them to market themselves. This may be thought of as 'purposive outflows' of knowledge, rather than the 'purposive inflows' that is primarily our interest.
} 
industry will be more or less cognitively proximate. However, as we argue below, cognition has both a structure and a content and, whilst the content may be similar regardless of location, structure is likely to vary. This is consistent with elaboration of a knowledge-based theory of geographical clusters (Maskell, 2001; Malmberg and Maskell, 2002). This body of work holds that "social affinity, cultural community and cognitive proximity tend to follow from spatial proximity...[which leads to]...processes of localized learning that are inherent in the everyday life of people working - and living - in any local setting” (Maskell and Malmberg, 2007, p. 607). Thus, over and above sectoral considerations, location contributes to the creation of (shared) interpretative frameworks through which meaning is established and learning takes place.

The national and regional systems of innovation literatures have long documented persistent and pervasive differences between locales that influence perceptions, practice and knowledge stocks (Cooke, Uranga and Etxebarria, 1997). Of course, some of the diversity provided through remote collaboration will relate to accessing new knowledge. As Bertrand and Mol (2013, p. 753) suggest: "knowledge resources are more homogeneous within a country and more heterogeneous across countries". However, we argue that even if the content of a partner's knowledge is similar, geographical dispersion makes it more likely that new things can be learned in terms of how this knowledge can be combined and applied. In her work on international research teams funded by the Finnish government, Hautula (2011) noted that cognition has both content and structure. While the content of knowledge includes the substantive (scientific, technical) knowledge that individuals hold, structure refers to how these elements are connected and applied. Crucially, across contexts, people differ in how they organize, or structure, knowledge 
into mental models. The content of individuals' (and organizations) cognition may be easy to replicate, but the structure is likely to remain tacit and to vary between researchers in different places (Hautula, 2011). Studies of dispersed teams report similar findings: at different locations a great variety in approaches to similar tasks is found, which are typically taken for granted but in practice hard to learn (Sole and Edmondson, 2002). Related evidence can be found in the diverse evolution of same-sector clusters across locations, for example the polymer-based and biomedical clusters in Ohio and Sweden (Johansson, Cetindamar, Carlsson and Braunerhjelm, 2000).

A mirror argument to the above, may point to the limitations of local collaborations. At its starting point, one might note a 'stylized' fact in the innovation literature: that knowledge spillovers are primarily local. Comparisons of patent citations and the cited patents, for example, show that knowledge diffusion to other economic actors happens slowly and is initially local (Jaffe et al., 1993; Ponds, van Oort and Frenken, 2010). It is also well established that within regions, knowledge spillovers are rooted in a shared culture of trust that develops by numerous mechanisms, including the mobility of workers (Almeida and Kogut, 1999), shared socialization during schooling or training (DiMaggio and Powell, 1983), and informal contacts that arise through professional associations, casual meeting places, and other social contacts that take place between people within the same geographical space (Saxenian, 1994). Geographical proximity reduces the cost and increases the frequency of personal contacts that build social relations between players in a network, thereby facilitating the flow of knowledge. However, the knowledge that flows in these relations is likely to be confined to the "provincial news and views" (Granovetter 1983, p. 202). It is likely to be familiar, to 
provide reassurance, but to be largely redundant. It is cognitively proximate in terms of structure and, often, in terms of content. The implication being that geographically proximate partners are, ceteris paribus, less likely to offer new complementary knowledge or to be the source of creative abrasion.

In other words, local knowledge search poses the risk of lock-in and overembeddedness (Eisingerich, Bell and Tracey, 2010; Rosenkopf and Almeida, 2003), while remote collaboration can be helpful to find and absorb complementary knowledge. With increased distance, the scope and supply of potential partners will also increase, and in this context scholars have emphasized the benefits of recombining distant knowledge across contexts (Rosenkopf and Almeida, 2003; Rosenkopf and Nerkar, 2001; Singh, 2005; Eisingerich et al., 2010).

Beyond their anticipated greater diversity, remote innovation partners may also be more valuable as a result of selection. Where the mechanisms that underpin local knowledge transfer (e.g. individual mobility, social networking, frequent face-to-face meetings) are more limited, remote collaboration imposes greater risks. Accordingly, firms may be willing to start such collaborations only if they perceive them as potentially highly valuable and after careful screening. This would imply a selection effect rather than a treatment effect - viz. only 'good' firms engage in distant collaboration and only with 'good' partners. In this vein, Tallman and Phene (2007) found that a firm's innovative capability (indicating the potential usefulness of its knowledge base to the recipient firm) is positively related with knowledge flows in international (versus national and regional) collaborations. 
Regardless, we follow Bertrand and Mol (2013) and argue that collaborating with remote partners involves a greater cognitive distance (Nooteboom, Vanhaverbeke, Duysters, Gilsing and van den Oord, 2007) and fosters innovation through creative recombination of heterogeneous inputs (Rodan and Galuncic, 2004). The relative valence of the treatment and selection effects is not clear, $a$ priori. This is unproblematic in formulating our hypothesis, since both indicate a positive relationship between innovative performance and remote collaboration. In our analysis we are able to provide a test for the selection effect, and the consequences for the direction of argumentation are detailed subsequent to that. In the meantime, our reading of the literature favors a stronger treatment effect. That is, at greater geographical distance firms may anticipate higher diversity of potential innovation partners; such that they are more likely to find new complementary knowledge. In line with these arguments studies have empirically identified that collaboration at greater distance is positively related with indicators of innovation performance. In their study of German mechanical engineering SMEs, Grotz and Braun (1997) noted that "local sub-contractors mainly perform low-level production operations", while the "more crucial and innovation-oriented ties are very often national or international in character" (p.549). Freel (2003) found for Scottish manufacturing SMEs that novel innovators were more likely to have distant partners than firms with only incremental innovations. Tödtling and colleagues (2006) noted that high-technology firms were both more likely to be engaged in international collaborations and to have pursued new to the market innovations. Miotti and Sachwald (2003) showed that for French businesses, collaboration with foreign partners was positively related with the share of turnover from new products, especially when transatlantic collaboration was 
involved. And, more recently, Bertrand and Mol (2013) examined the R\&D outsourcing of R\&D-intensive French firms and observed positive innovation performance effects of foreign outsourcing that were not present for domestic outsourcing. Foreign outsourcing of R\&D was positively associated with increased product innovation, although it has no effect on process innovation. In contrast, domestic outsourcing of R\&D was observed to have a negative effect on both product and process innovation. Following these theoretical and empirical observations, we hypothesize that:

\section{H1: In high-tech small firms, there will be a positive relationship between their} extent of remote collaboration and innovative performance.

\section{$R \& D$-intensity}

Classic economic accounts assumed that, compared to knowledge creation, the costs of knowledge transfer were small and negligible: "like a radio signal or smoke pollution, its effects are thought to be costlessly realized by all firms located within the neighborhood of the emission" (Cohen and Levinthal, 1989: p.570). Today, however, it is recognized broadly that knowledge transfer can be a daunting task. Although remote collaborators may be more likely sources of diversity, the spatial distance creates challenges, as interpersonal contact is more limited and hard to organize, and typical mechanisms that aid to knowledge transfer (such as labor mobility and personal social networking) are retarded. To undertake remote collaborations, firms must bridge the cognitive distance between themselves and their partners (Bertrand and Mol, 2013). This challenge is evident in, for instance, the distance decay functions in communication observed by Howells (1999), such that the rate of contact between partners falls approximately with 
the square of their separating distance. In a similar vein, Hoekman and colleagues (2010) found that within Europe, despite policies to create a European Research Area, academic research collaboration is still very sensitive to geographical proximity. Singh (2005), in a study of knowledge flows between individual inventors of any two patents, found that knowledge flows within the region were stronger than those across regional boundaries. He also found that the existence of a direct tie was associated with greater probability of knowledge flows, with the probability decreasing as the path length increased. Studies of knowledge spillovers in Europe indicated spillover reach to have an upper bound of 300 kilometers (Botazzi and Peri, 2003) or 400 kilometers (Greunz, 2005). Whilst the difference in absolute distances is likely to reflect, amongst other things, differences in transport infrastructures, population densities, and travel norms, a key issue is that they seem intended to represent the distance that people can and want to conveniently travel. As an upper limit to define remoteness, people seem to maintain a threshold of a single day to travel back and forth (in our empirical analysis presented later, we will apply various geographical distance thresholds to operationalize remote collaborations).

In short, remote collaboration poses additional challenges, and the ability to overcome these challenges is unlikely to be evenly distributed across firms. We suggest that different commitments to internal R\&D will associate with different capabilities to overcome the challenges of remote collaboration; such that higher R\&D intensities will allow firms to better find, transfer and exploit knowledge from remote collaboration partners. This is an absorptive capacity argument (Cohen and Levinthal, 1989; 1990). Beyond its direct instrumental role in the development of innovations, high R\&D 
engagement indicates that a firm is capable of absorbing new knowledge (Cohen and Levinthal, 1989; Muscio, 2007; Rothaermel and Alexandre, 2009).

In their recent study of R\&D-intensive French firms, Bertrand and Mol (2013) argue that firms with larger absorptive capacities, proxied by internal R\&D intensities, will be better able to outsource R\&D "to more cognitively distant offshore suppliers" (p. 753) and that absorptive capacity would be "more important for offshore outsourcing as it involves a larger cognitive distance" (p. 753). The analysis these authors perform is broadly analogous to the work presented here. Whilst they were concerned with R\&D outsourcing at a distance, our concern is with remote collaboration. Similar challenges associated with cognitive distance are likely to be at play in benefitting from both outsourcing and collaborating remotely.

Absorptive capacity is defined as the ability to recognize, adopt and apply external knowledge, and is determined by investments that contribute to accumulated knowledge (Cohen and Levinthal, 1990). In making an absorptive capacity argument, one must guard against its reification (Lane, Koka and Pathak, 2006). Lane et al. (2006) have elaborated a process perspective on absorptive capacity underpinned by learning processes concerned with exploration, transformation and exploitation. Fundamental to these learning capabilities is a firm's stock of prior knowledge. This is consistent with the original absorptive capacity thesis, which held that "at the most elemental level, this prior knowledge includes basic skills or even a shared language, but may also include knowledge of the most recent scientific or technological developments in a given field" (Cohen and Levinthal, 1990: p.128). 
Given our focus on R\&D intensity, we inevitably neglect part of what constitutes absorptive capacity. Prior related knowledge accumulates with firms' R\&D investments, but also with non-technical experience obtained from interactions with customers, former alliances with other firms, and learning-by-doing (Zahra and George, 2002). Nevertheless, , technological knowledge is usually considered to be central to the knowledge that a firm explores, transforms and exploits in its absorptive capacity processes, and we suggest that in our sample of high technology firms, prior technological knowledge is the primary constituent of absorptive capacity.

Central to our argument is that higher absorptive capacities (i.e. higher R\&D intensities) will endow firms with the capabilities to overcome the additional challenges attendant upon remote collaboration. Generally, this is about ameliorating increased cognitive distance - the difficulty involved in recognizing, evaluating and productively interacting with organizations whose collective cognition (in structure and content) differ substantially. More specifically, this is likely to revolve around three effects.

First, high R\&D intensity enables firms to more effectively search for remote innovation partners. Cohen and Levinthal (1990) already noted that "critical knowledge does not simply include substantive, technical knowledge; it also includes awareness of where useful complementary expertise resides (...) outside the organization. This sort of knowledge can be (...) who knows what, who can help with what problem, or who can exploit new information" (p.133). Moreover, Arora and Gambardella (1994) found that "firms with better ability to evaluate (collaborative R\&D projects) are more selective and focus on (...) more valuable linkages" (p.109). In contrast, at low absorptive capacity, relevant external knowledge is much harder to identify. It implies that the scope of 
external search is more constrained by firms' existing knowledge, and that R\&D investments improve a firm's search capabilities. We suggest that these better search capabilities are particularly useful to find remote collaboration partners, as familiar mechanisms to be informed about partners (e.g., social networking) are less likely to be present or are present in less intense forms only.

Second, high R\&D intensity enables firms to more effectively transfer knowledge from remote partners. While drawing an analogy with transferring a recipe, Sorenson, Rivkin and Fleming (2006) state that "once a useful innovation has been located, transferring its recipe, even between cooperative actors, can fail (...) The recipient rarely grasps the original recipe completely, due to imperfections in the transfer process. Gaps emerge in what the sender conveys - perhaps the chef forgets an ingredient or skips a step - and the receiver may misinterpret some of the information that is transmitted" (p.997). Again, in the case of remote collaborations private information cannot be accessed via persistent personal presence or close networks. Hence, effective knowledge transfer will depend more on a firm's internal stock of knowledge, which is helpful to develop assimilation routines and processes that allow absorption from outside sources (Cohen and Levinthal, 1990; Arora and Gambardella, 1994; Sorenson et al., 2006). Firms with higher levels of absorptive capacity are able to "manage communications with their alliance partners more effectively" (Rothaermel and Alexandre, 2009: p.764).

Third, high R\&D spenders should do a better job of exploiting the knowledge obtained from remote partners. This knowledge is more likely to be distinct from and a complement to what the firm already knew, or in the words of Sorenson et al. (2006) the “...ingredients and cooking experience of the receiving chef rarely match identically 
those of the sender" (p.997). High R\&D intensity in the receiving firm indicates enhanced technological capabilities that are helpful to process and exploit knowledge internally. As Cohen and Levinthal (1990) already noted: "those who are attempting to encourage cooperative research ventures (...) should recognize that the direct participation in the venture should represent only a portion of the resources that it will take to benefit (...). Participating firms also must be prepared to invest internally (to) permit effective exploitation of the venture's knowledge output" (p.149). Investments in $\mathrm{R} \& \mathrm{D}$ enable firms to resolve the tensions that may exist between the dynamics of external and internally technology sourcing. In their study of 141 US manufacturing firms, Rothaermel and Alexandre (2009) observed that R\&D intensity moderates the relationship between technology sourcing and firm performance such that the positive effect of combined internal and external technologies on firm performance is stronger at higher levels of R\&D. Similarly, Berchicci (2013) found that Italian firms with greater $\mathrm{R} \& \mathrm{D}$ intensity are able to benefit more from their external partners by using a smaller share of external $R \& D$ activities.

In summary, investment in the technology component of absorptive capacity makes things more familiar, and makes more things familiar. This, in turn, helps firms overcome the additional search, transfer and exploitation costs imposed by remote collaborations. We hypothesize that:

H2: The higher the R\&D intensity of high-tech small firms, the stronger the relationship between their extent of remote collaboration and innovative performance, and vice versa. 


\section{METHOD}

We used data from an existing survey of high-tech small firms in the Netherlands. This survey was commissioned by the Dutch ministry of economic affairs and conducted in the spring of 2006. While high-tech small firms are the target group of most Dutch innovation policies, their characteristics were poorly recorded in the official statistics at the time. The survey included indicators related to the innovation characteristics of hightech firms and their collaborators.

All participants were members of a panel of high-tech small firms that was created for systematic data collection. To qualify, firms were not allowed to have more than 100 employees. They also had to be active R\&D performers as defined by the Frascati manual (OECD, 2002), and to have developed new technology-based products in the past three years - innovation is central in how these firms make their living. Participants were operating in a broad range of industries, including manufacturers of chemicals, rubbers and plastic products, manufacturers of machinery and equipment, technical wholesale traders, IT and telecom firms, engineers and commercial R\&D firms.

All 675 high-tech small firms in the panel were invited to take a web survey. Eventually 379 firms participated, a response rate of 56\%. Respondents were all small business owners or general managers. Compared to the sampled firms, $\chi^{2}$-tests indicated that respondents and non-respondents were similar in terms of industry types $(p=.56)$ and size classes $(\mathrm{p}=.59)$. For the current paper, we analyzed data from 248 firms who had reported innovation collaborations with other organizations in the past three years, and for whom none of the variables reported hereafter were missing. Again, compared to the 
full panel $\chi^{2}$-tests suggested no selection bias in terms of industry types $(p=.19)$ and size classes $(\mathrm{p}=.57)$.

\section{Dependent variable}

The dependent variable is the innovative performance of high-tech small firms. As an indicator, we use the share of revenues obtained from new products introduced in the past three years. For high-tech small firms new product introductions are at the heart of their competitive strategy, so this measure is most relevant. It directly measures the success of new technology-based products in the market, and can be considered a key performance indicator. This indicator has been frequently used to analyze innovative performance (e.g., Cassiman and Veugelers, 2006; Escribano et al., 2009; Laursen and Salter, 2006; Tsai, 2009). New product revenue share also correlates considerably with alternative performance indicators like patent registrations, especially for high-tech firms (Hagedoorn and Cloodt, 2003).

Respondents had reported their share of past year's revenues obtained with new products (not more than 3 years old). Where a precise indication could not be given, they were offered a range of categories, including 'less than $1 \%$ ', ' 1 to $<5 \%$ ', ' 5 to $<10 \%$ ', etc. We then substituted the category means (e.g., ' 1 to $<5 \%$ ' becomes $3 \%$ ) for our subsequent analysis. Overall, the firms in our sample reported a share of new product revenues of $45 \%$. We log transformed these scores to reduce the problem of nonnormality of the residuals (see hereafter).

\section{Independent variables}


To measure remote collaboration we used the share of remote partners (SORP) in the total number of innovation partners, as reported by respondents. Respondents had first indicated if their firm had collaborated in any innovation projects in the past three years, defined as 'active participation in joint innovation projects with other organizations. The partners need not derive immediate commercial benefit from the venture. Pure contracting out of work, where there is no active collaboration, is not regarded as collaboration' (OECD/Eurostat, 2005, p.79). If yes, they provided a full list of their collaboration partners including their place of settlement and country. A specific cue was offered to support adequate recall, again taken from the Oslo Manual: 'Collaboration partners may either be other enterprises (e.g. competitors, suppliers, customers, any others) or non-commercial institutions (e.g. public research organizations, universities)' (OECD/Eurostat, 2005, p.79).

Public surveys usually record geographical distances on nominal scales (e.g., 'Are your partners in your region, country, or abroad?'), and previous studies have applied similar remoteness indicators (e.g., Ponds et al., 2010; Tallman and Phene, 2007; Drejer and Vinding, 2007). Here, we could use much more precise data. On average respondents had reported details of 4.68 partners, with a minimum of one and a maximum of fourteen. Seventy-eight percent of the reported partners were from the Netherlands, while $7 \%$ came from Germany and 2\% from Belgium. More distant partners were located in the United States (2\%), United Kingdom (2\%) and 32 other countries including Australia, Canada, China, France, Japan and Russia.

Drawing on route planning software we computed the approximate geographical distance to each collaboration partner. If partners were settled in the same town, the 
geographical distance was assumed to be one kilometer. As people maintain different standards of remoteness, and that travel infrastructures and norms may be diverse, we acknowledge the definition of remoteness is somewhat arbitrary. We therefore applied a range of thresholds by computing the share of remote partners at various spatial levels, including 500, 750 and 1000 kilometers. These are generally distances that are too demanding to travel back and forth in a day, but rather require people to fly out and/or stay overnight in order to meet in person. Hereafter we first present our results for the share of remote partners $>750 \mathrm{~km}$. The average share of remote collaborators was then $10 \%$, indicating that most partners were in fact at close range. Other thresholds were applied as robustness checks (see later). ${ }^{2}$

For R\&D intensity, respondents had reported their firms' R\&D expenditures as a percentage of sales revenues over the past year. In line with our discussion in the theory section, R\&D intensity indicators have been applied in previous studies for technologyoriented absorptive capacity (e.g., Cohen and Levinthal, 1989; 1990; Nieto and Santamaria, 2007; Rothaermel and Alexandre, 2009). R\&D-based measures are considered suitable to comprise the absorptive capacity of high-tech firms (cf. Muscio, 2007). Like with new product revenue share, if respondents had not been able to report exact percentages, the survey had offered a range of categories, and we substituted those with their middle numbers (e.g., ' 1 to $<5 \%$ ' becomes $3 \%$ ). The average estimated R\&D intensity in the sample was $25 \%$.

Finally, we included a variety of control variables: collaboration volume, innovation ambition, firm size, firm age and technology-industry dummies. We controlled for collaboration volume - the number of reported partners - as past studies on

\footnotetext{
${ }^{2}$ At the thresholds of 500 and $1000 \mathrm{~km}$, the share of remote partners was $15 \%$ and $8 \%$, respectively.
} 
innovation networking typically show that volume matters for innovation performance (e.g., Oerlemans et al., 1998). Thus, our analysis revealed if and to what extent remote collaboration matters over and beyond the impact of the volume of collaboration.

The second control variable was firm size, indicated by the number of employees in fulltime equivalents. Size is a well-known determinant of the innovativeness of firms; for example, by influencing the ability to finance innovation-related investments, to spread risks, and to organize innovation (Nooteboom, 1994). Given that all respondents in the sample are innovative firms, we anticipate a negative relationship between size and the share of new product revenues, that is, small firms are less likely to innovate, but when they do it is generally with greater intensity (Nooteboom, 1994). The average firm size in our sample was 19.0 fulltime equivalents. Since the variable was highly skewed to the right, we log transformed it before entering it into our regression analyses (see later).

The third control variable was the age of the firm, indicated by the number of years since its establishment. Especially young enterprises are more likely to report high shares of new product development revenues and R\&D-intensity. On average, firms in our sample were 15.7 years $($ minimum $=1$; maximum $=136)$. Only $12 \%$ was aged three years or less, while $25 \%$ was five years or less, and $50 \%$ was at most eight years old. In our analyses we log transformed firm age, as its raw distribution was skewed.

The fourth control variable was innovation ambition, indicated by the claimed strategic importance of product development. Firms with high innovation ambitions may collaborate with technologically more advanced and specific partners, who may generally be further away - so that innovation ambition would be an alternative explanation for any observed relationship between remote collaboration and innovation performance. We 
added a dummy control variable indicating the importance of product development to the business.

Finally, we included dummies for the technology area in which a firm reported to be most active: electronics/electro-mechanical, chemical, bio/food, ICT, energy, construction, and machinery/production technology. Industry-technology effects are also important in explaining variance in innovative activity (Cohen, 1995). Moreover, some technological areas are marked by greater environmental dynamism, which directly affects the share of new product revenues (young and fast-growing technology areas versus established ones). Electronics and electro-mechanical firms were treated as the reference group and not included in the analysis.

\section{Descriptive statistics}

Table 1 gives the descriptive statistics for the firms in our sample. We observed significant correlations between the share of new product revenues and the share of remote partners $(>750 \mathrm{~km})$. Correlations with $\mathrm{R} \& \mathrm{D}$ intensity were also significant, as were firm size and firm age. Moreover, some of the independent variables were correlated, the largest single correlation being between firm size and firm age $(r=.64)$. These correlations did not indicate any concerns for multicollinearity. Indeed, in the regression models reported hereafter variance inflation factors never exceeded the value of 2.0 .

[TABLE 1 ABOUT HERE]

\section{RESULTS}


We conducted Tobit regression analyses, a form of regression used when the dependent variable is censored. Such analyses are warranted when the dependent variable has clear boundaries - in our sample three firms reported a minimum share of new product revenues, while 35 firms reported that $100 \%$ of their revenues were from new products. Following previous research (e.g., Laursen and Salter, 2006) we log transformed the dependent variable to reduce the problem of non-normality of the residuals. After log transformation, our dependent variable had a skewness of -.87 and excess kurtosis of .40, while for the untransformed variable these measures were .40 and -1.30 , respectively. The untransformed dependent variable gives nearly identical results and is reported later as a robustness check. For the independent variables, we centered the share of remote partners and R\&D intensity around their means, and computed their interaction term by multiplying these centered values in order to ease the interpretation of any significant interaction effect (Aiken and West, 1991). We then estimated various specifications of the model to test our hypotheses (Table 2). Goodness-of-fit was assessed by comparing the difference in the transformed loglikelihood value $(-2 * \mathrm{LL})$ with a previous (hierarchically nested) model and tested against a $\chi^{2}$-distribution.

\section{[TABLE 2 ABOUT HERE]}

The first model included R\&D intensity and all control variables. In line with previous work, the effect parameter of $R \& D$ intensity was positive $(b=.547)$, but only marginally significant $(\mathrm{p}<0.10)$. It implies that after including all control variables, the larger the share of revenues spent on $R \& D$ the higher the share of new product revenues. It was 
also confirmed that firm age is negatively associated with the share of new product revenues, while no effect of size was found. The number of collaboration partners, echoing previous empirical findings, was positively related with new product revenue shares $(b=0.0791, p<0.01)$.

The second model added the share of remote partners, here defined as those further away than 750 kilometers. This model tested our first hypothesis that more intense remote partnering is positively associated with innovation performance. As model fit improved significantly, and the effect parameter of the share of remote partners was positive and significant $(b=1.035, \mathrm{p}<0.01)$, this hypothesis is confirmed.

The third model then tested the moderating role of R\&D intensity. Compared to the previous model, goodness-of-fit improved significantly and the effect parameter was significant as well $(b=5.078, p<0.01)$. To evaluate the significant interaction effect, we rearranged the regression equation into simple regressions of the share of new product revenues, with the share of the remote partners as the focal independent variable, and at conditional values of R\&D intensity. Following Aiken and West (1991), we evaluated these regressions at high scores for the moderating variable (one standard deviation above the mean of R\&D intensity), at its average score, and at low scores (one standard deviation below the mean). See Figure 1.

\section{[FIGURE 1 ABOUT HERE]}

At average $R \& D$ intensity the share of remote partners was positively associated with new product revenue share. At high values $(\mathrm{R} \& \mathrm{D}$ intensity $=50 \%)$ the relationship 
becomes more pronounced: remote collaboration is even stronger related with innovative performance $(b=2.446, p<0.001)$. In contrast, at low values of $R \& D$ intensity (i.e. $0 \%)$ the relationship is slightly negative and no longer significant $(b=-0.098, p>0.1)$. These findings imply that the higher the R\&D intensity of high-tech small firms, the more they are able to benefit from remote collaboration. Our second hypothesis is supported.

\section{Robustness checks}

We estimated a range of alternative models to explore the robustness of our findings.

First, we were concerned if our findings were robust to alternative thresholds of 'remoteness'. Thus, we re-estimated our models with the share of remote partners at various spatial levels, initially imposing thresholds between 250 and 1000 kilometers, and later also with other thresholds. We found that at low thresholds (250 km or less) both the main and interaction effect were not significant. At 300 kilometers the direct effect of the share of remote partners was still not significant $(b=0.387, p=0.17)$ while the interaction effect became marginally significant $(b=2.13, p=0.09)$. Full significance was consistently obtained at thresholds of 650 kilometers and more. At 650 kilometers the direct effect parameter was $b=0.844(p=0.018)$ and the interaction effect parameter was $b=5.120(p=0.002)$. At 1,000 kilometers these estimates were $b=1.230(p=0.003)$ and $b=5.171(p=0.009)$, respectively.

An alternative definition of remoteness was obtained by regarding all collaboration partners outside the Netherlands and its neighboring countries: Belgium and Germany (as we had noted that most German partners in our data were located near the Dutch border, so traveling to meet in person can be done in a day). Again, both effects 
were positive and significant. The direct effect parameter was $b=0.942(p=0.001)$ and the interaction effect $b=4.768(p=0.005)$. When we also regarded France and the United Kingdom as neighboring countries, the interaction effect became more pronounced while the direct effect remained significant. In general, we found that the higher the threshold for remoteness, the stronger the empirical support for our hypotheses.

Second, we explored if our results would be maintained if the number of remote partners would be used rather than their share. After including the number of remote partners $>750 \mathrm{~km}$ the direct effect was again significant $(\mathrm{b}=0.253, \mathrm{p}=0.003)$, and ditto for the interaction term $(b=0.840, p=0.01)$.

Third, we checked if our findings were sensitive to alternative specifications of the dependent variable. Without log transformation of the share of new product revenues our findings were maintained. We also computed the log-odds ratio for the dependent variable - defined as $\log (\operatorname{share}$ newprod$/(1$ - share newprod $))$ - to obtain an alternative dependent variable which was continuous, normally distributed, and not censored. We then repeated all analyses drawing on OLS regression models, and found nearly identical results. Detailed results of the aforementioned robustness checks are available on request. Next, we addressed a potential endogeneity issue. The choice of collaborating with remote partners could be endogenous to the firm's strategy. For example, firms dealing with complex and innovative problems may find only few suitable partners to work with for a common technological solution. As such partners are rare and, on average, likely to be found at greater geographical distance, focal firms would need to purposely search for them. ${ }^{3}$ To account for such endogenous choice, we needed to find suitable instrumental variables that are related to the endogenous explanatory variable

\footnotetext{
${ }^{3}$ We thank one of the reviewers for pointing out this alternative explanation.
} 
(SORP), but do not correlate with the error term in the explanatory equation. For this purpose, we employed two variables as instruments: the average distance (in $\mathrm{km}$ ) to the firm's three most important customers and the share of export revenues. These variables satisfied both aforementioned conditions: correlated with the share of remote partners but uncorrelated with the explanatory equation. When modeling these instrumental variables we assume that firms actively selling products abroad have better opportunities to search for and engage with remote innovation partners. Moreover, since they are selling in international markets, they are more 'visible' to other firms and therefore more likely to engage in innovation partnerships.

Model 1 in Table 3 presents the results of the second stage of a Tobit estimation using the two instrumental variables. The number of observations was now 221 due to missing values in the "average distance from customers" variable. Nevertheless, the coefficient of SORP is positive and significant at $\mathrm{p}<0.05$, suggesting that our overall results hold. The instrumental variables tobit model, however, does not allow us to fully test whether the IVs chosen are valid exogenous variables. To do so, we first ran an additional estimation using a two-stage-least-square regression and then we estimated the Sargan's statistic test (often called the test of over-identifying restrictions), which is suitable for our purpose. Model 2 reports the outcome of the estimation, whose results are almost identical to the ones from Model 1. It also shows a p-value $>0.8$ for the overidentification test, which suggests that we fail to reject the null hypothesis - that is, we have some confidence that the employed instrumental variables are exogenous. (As for the interaction effect, we could not conduct a similar analysis. It would require 
instruments exogenous to both R\&D intensity and the interaction term, and in practice such models are hard to estimate.)

\section{[TABLE 3 ABOUT HERE]}

As final note, one could argue that firms with high R\&D intensity are more likely to be visible in international markets and thus more likely to get partners far away. This would mean a significant correlation between $R \& D$ intensity variable and share of distant partners variable. To test this conjecture, we ran regression models with R\&D intensity as regressor and share of distance partner as dependent variable, but we find no significant correlation within our sample. Thus we have some initial evidence that firms with high R\&D intensity do not necessarily have an advantage in building relationship with distant partners.

\section{DISCUSSION}

Our interest in the current paper was primarily in examining the moderating effect of $R \& D$ intensity on innovation performance in remote collaborative ventures. We hypothesized that high-tech firms' engagement in remote collaboration was positively associated with their innovation performance, even when controlling for the volume of collaboration. Thereafter, holding that geographical distance brings additional challenges to search, transfer and exploit (tacit) knowledge, we explored if firms' R\&D intensity positively moderated the relationship between remote collaboration and innovation performance. We were able to test our hypotheses with unique survey data drawn from 
248 high-tech small firms, including the actual kilometric distance to their innovation partners.

As for the direct relationship, in line with previous empirical observations we found that remote collaboration is positively associated with the share of new product revenues. This finding corresponds with our reasoning that at greater distance firms are more likely to find diverse and complementary knowledge. Especially when faced with challenging innovation problems that promise greater innovation returns, the rarity of potential collaboration partners is likely to lead to them being, on average, further away. Our finding is also in line with past studies showing that the scope and supply of potential partners increase with distance (Rosenkopf and Almeida, 2003); that diversity in the structure of cognition across locales may be an important source of variety (Hautula, 2011); and that, at great distance, formal collaboration may compensate for the lack of less formal knowledge transfer mechanisms (e.g., labor mobility, personal meetings) found in local innovation systems (Ponds et al., 2010).

Of course, the observed direct relationship between remote collaboration and innovation performance also fits with a selection interpretation. That is, given the additional challenges associated with remote collaborations, firms are only likely to engage in them when the anticipated benefits are high. ${ }^{4}$ In our initial analyses, we attempted to control for this effect by including innovation ambition in our models. Morever, our instrumental variables regression for the direct relationship between remote collaboration and innovation performance supported our initial presuppositions. Nevertheless, we acknowledge that more robust evidence for the hypothesized relationship would require longitudinal data - as Bertrand and Mol (2013) recently

\footnotetext{
${ }^{4}$ We are grateful to one of the reviewers for suggesting this line of argument.
} 
demonstrated for a similar hypothesis concerned with remote $R \& D$ outsourcing rather than remote innovation collaborations.

As for the second hypothesis, our findings suggest a contingent effect of R\&D intensity on the relationship between remote collaboration and innovation. To this end, we note that $R \& D$ intensity moderates the relationship between remote collaboration and innovative performance, in such a way that at high $R \& D$ intensity the relationship is stronger and more significant, while at low values the relationship disappears. We rationalize our findings in terms of absorptive capacity. To the extent that the greater cognitive distances involved in remote collaborations are an important source of diversity, remote collaborations associate with higher innovation performance. However, greater cognitive distance entails challenges in identifying suitable partners, effectively communicating or transferring new complementary knowledge and exploiting the newly acquired knowledge. An enhanced absorptive capacity positions firms to better overcome these additional challenges.

Importantly, in the current study, our view of absorptive capacity (bound up in its measurement as R\&D intensity) is partial. The learning processes associated with absorptive capacity are underpinned by capabilities that rest on prior knowledge which can also be non-technological. In our research context of high-tech small firms, however, it is technological knowledge that firms essentially explore, transform and exploit. Following this, it is likely that an absorptive capacity built on prior technological knowledge is a necessary condition for innovation performance - if not a sufficient condition. 
More practically, our result suggests that high-tech small firms with higher R\&D intensities are more likely to successfully engage in and benefit from remote collaborations. The patterns that we observed in our data suggest that such firms are better able to select remote partners, to transfer their (tacit) knowledge, and to exploit this knowledge for better innovation performance. Again, however, an alternative (selection) explanation may be plausible. First, for example, valuable partners are rare and on average far from a focal firm's location. Second, firms with high new product revenues and $R \& D$ intensities may be perceived as better innovation partners especially by remote parties - who otherwise have difficulty in assessing their potential usefulness and take firm innovativeness as an indicator. In other words, both innovation performance and engagement in $R \& D$ are associated with remote collaborations, not in any causal manner, but because they signal to potential partners firm quality. This implies a selection phenomenon: if it is more difficult to identify potential partners and to assess their quality if they are far away, firms are likely to be drawn largely to highly visible partners. Given the stated motivation for collaboration, 'visibility' is likely to be related to capabilities in $R \& D$ and innovation. It is this source of endogeneity that we attempt to address in the final robustness test described above. That our results hold gives us confidence in our interpretation, although we are not able to address all endogeneity issues. Therefore, our results should be taken with caution while we would welcome further work that clarifies our results.

Regardless, in simple terms this finding extends recent empirical studies in which measures of R\&D intensity moderated the impact of external knowledge sourcing indicators, including the volume of knowledge sourcing (Escribano et al., 2009), 
ambidextrous technology sourcing (Rothaermel and Alexandre, 2009) and collaborations with specific types of partners (Tsai, 2009).

Moreover, we found that the higher the cut-off to classify collaborators as 'remote', the stronger the moderating role of R\&D intensity. The strength and significance of our moderation hypothesis increased the more the spatial threshold was raised. Simultaneously, when we operationalized remoteness in terms of country location (i.e. considering Belgian and German partners as 'close' and others as remote; and considering Belgian, German, French and British partners as 'close' and others as distant), we found a stronger interaction effect as 'remoteness' became tightly defined. These results are in line with earlier studies, which suggest that at increasing geographical distance, knowledge transfer is increasingly complicated (Singh, 2005; Howells, 1999). It can be inferred that at larger distances problems with knowledge transfer become more acute, such that R\&D intensity (reflecting a technologically focused absorptive capacity) becomes important as a potential fix or enabling factor.

We should stress that most high-tech small firms in our dataset were inclined to collaborate locally. The average share of remote partners - located at $750 \mathrm{~km}$ or more was only 10 percent. At thresholds of 500 and $250 \mathrm{~km}$ these percentages were $15 \%$ and $17 \%$, respectively. This result echoes many studies in economics, management and geography that found that most collaborative efforts do not reach very far (e.g., Hoekman et al., 2010; Ponds et al., 2010). It reflects the barriers that firms face to effectively engage in distant collaboration, but it may also indicate a general lack of willingness and/or perceived necessity to try going further, especially when sufficient diverse partners can be found at close range. Notwithstanding a firm's motivation, our empirical 
findings suggest that some degree of R\&D intensity, reflecting enhanced technologyfocused absorptive capability, is needed to collaborate effectively at greater distance.

It must also be noted that recent studies suggested that geographical proximity is increasingly less important for successful collaboration. Tallman and Phene (2007)'s analysis of biotech patents challenges the common view that knowledge flows are inversely related to the distance of separation. In some of their cases geography did not matter for patent citations, while in other cases the impact of geographic proximity even ran counter to their hypothesizes. Herrmann, Taks and Moors (2012), in an analysis of Flemish biotech firms, found that geographic proximity was negatively related to the intensity of collaborative efforts. They concluded that geographic proximity is not a necessary condition for collaboration, and that in an ever globalizing world, decreasing transportation and communication costs enable collaborations at greater distances.

The explanation for these deviant findings may be that the biotech industry includes mainly firms with very high R\&D intensities. Such firms are usually university spin-offs marked by high R\&D expenditures compared to their overall revenues (van Beuzekom and Arundel, 2009). Hence, biotech firms will likely have the technologybased absorptive capabilities that enable them to more effectively engage in, and benefit from, remote collaborations. In this context, Moodysson and Jonsson's (2007) qualitative study of Swedish biotech firms showed that remote collaborations were indeed relatively common, but mainly driven by necessity, that is, the need to obtain highly specialized knowledge. Moodysson and Jonsson also concluded that local collaboration was perceived as much more convenient and preferable, especially when tacit knowledge had to be transferred, while global collaboration introduced the kind of transfer challenges 
that we discussed earlier in this paper. In sum, the apparently deviant results for biotech firms may fit well with our empirical observations for a much broader group of high-tech small firms.

\section{Implications}

For managers and business owners we can infer from our findings that the success of distant collaborations is contingent upon internal commitments to research and development. What we are unable to determine is the extent to which this is a function of an enhanced capability to search for and identify suitable partners or improved communication and exploitation capabilities. Our intuition is that investments in $R \& D$ improve exploratory, transformative and exploitative learning capabilities, which, in turn, ameliorate the additional challenges associated with the greater cognitive distance of remote partners. Following this, the greater the geographical dispersion of their collaborative efforts, the more problems with finding suitable partners and managing knowledge transfer can be anticipated, and the stronger their incentive to engage in $R \& D$ as a possible fix.

Of course, managers will not engage in more $R \& D$ just to benefit from distant knowledge, but rather be interested in any direct relationship with their innovative output. Our results, however, show that the potential advantages of such engagement are broader, and also include the firm's ability to benefit from a broader supply of knowledge in a larger geographical area. In our sample of high-tech small firms R\&D intensity becomes particularly important for collaborations at distances over $600 \mathrm{~km}$; a distance at which personal interactions are generally limited due to travel infrastructures and norms. 
At minimum, managers should be concerned with their absorptive capacity to effectively select remote partners and to transfer and exploit their knowledge. Where high-tech small firms dedicate only a limited part of their revenues to $R \& D$, concentrating collaboration efforts on local partners would seem a preferable strategy. Beyond this, additional knowledge transfer mechanisms (including the personal networking of employees and the mobility of engineers) are likely to further ease the knowledge transfer process.

For policy makers our findings shed a new light on what hampers policy instruments focused on interactions at larger geographical distances. A first observation is that an increasing number of innovation policy instruments revolve around stimulating interactions between firms, or with public research organizations (Tsipouri, Reid and Miedzinski, 2008). Nearly all developed countries nowadays offer cluster policy programs which mostly still have a dominant national or regional focus (Oxford Research, 2008) ${ }^{5}$. A recent trend, however, is that the internationalization of cluster programs becomes increasingly important, for example by making subsidies eligible to foreign businesses. It is also recognized that remote collaborations take more effort, as participants generally prefer to find their partners locally, and that policies need to be modified to facilitate global knowledge search and transfer (OECD, 2008; Christensen, Meier zu Köcker, Lämmer-Gamp, Solgaard Thomsen and Olesen, 2011).

Our findings suggest that in order to effectively include high-tech small firms in any of these international programs, $R \& D$ intensity is key - either reflecting firms' ability to absorb diverse, distant technological knowledge, or to become better visible and look

\footnotetext{
${ }^{5}$ Oxford Research's (2008) inventory shows that about $50 \%$ of the cluster programs also include crossborder activities, but these are usually traditional export promotion schemes and trade missions, not support services for remote innovation collaboration.
} 
more attractive to remote innovation partners. Only half of the cluster programs are however focused on high R\&D performing businesses, while for one out of five programs R\&D engagement is even low (Oxford Research, 2008). Moreover, as a consequence of the Open Innovation model, many private enterprises appear to downsize their commitment to fundamental research (EIRMA, 2004). Our findings tentatively suggest that in such instances opportunities to benefit from remote collaborations will be modest.

To stimulate collaborations at greater distances, elements of traditional R\&D policies (e.g., tax credits, subsidy schemes) seem still merited; not so much as a direct determinant of innovative output, but rather to strengthen the absorptive capacity of hightech small firms. The lack of these capabilities may well explain why the participation of small firms in international subsidy schemes falls short of expectations (Arnold, 2009).

\section{Suggestions for future research}

Our study had some limitations that bring opportunities for follow-up research. As indicated, we tested our hypotheses on cross-sectional data, which prevented us from strong inferences regarding causality. Despite that our sample included only active R\&D performers engaging in product development, that we controlled for innovative ambitions, and that we estimated instrument variable regressions to control for the potential that our results simply reflected the 'visibility' of firms, we are necessarily cautious about drawing causal interpretations. Our tentative recommendations to managers and policy makers rest on the conclusion that firms must have resources to get resources (Eisenhardt and Schoonhoven, 1996). But we would be happy to see complementary longitudinal and case-study work to shed further light on the nature of the 
relationships we observe. In similar vein, we acknowledge that our data were singlesource. To empirically demonstrate that remote collaboration partners bring more diverse knowledge, analyzing dyadic data would be merited (e.g., as Nooteboom et al. (2007) demonstrated with patent data).

Beyond this, we have couched our arguments in familiar absorptive capacity terms - and we have used a familiar measure of absorptive capacity. We acknowledge that this only provides a partial perspective on the learning capabilities that underlie absorptive capacity. And, while we are comfortable in arguing that this makes sense in a sample of high-tech small firms, replicating and expanding our findings to other contexts like medium-tech or low-tech firms is likely to benefit from a broader conception which also better captures other forms of prior knowledge, especially non-technological knowledge.

Finally, while our focus was on geographical distance, we acknowledge that distance is not only a matter of spatial separation. Although geography creates boundaries and brings challenges, other types of proximity will partly determine the magnitude of these. Boschma (2005) for example distinguished five forms of proximity, including cognitive, organizational, social, institutional and geographic differences between collaboration partners. He suggests that geographic proximity is neither a necessary nor a sufficient condition for effective collaboration to emerge, but rather, that successful outcomes are also determined by other forms of proximity. Moreover, firms may develop alternative strategies to find diverse knowledge, for example by transcending local industry boundaries rather than by searching very far. In future research it would be 
interesting to measure these alternative concepts to see how they relate to innovative

performance, and if R\&D intensity moderates these relationships.

\section{References}

Aiken, L.S. and S.G. West (1991), Multiple regression: testing and interpreting interactions. Sage: Thousand Oaks.

Almeida, P. and B. Kogut (1999), 'Localization of knowledge and the mobility of engineers in regional networks', Management Science, 45, 905-917.

Arnold, E. (2009), Evaluation of the sixth framework programmes for research and technological development 2002-2006, European Commission: Brussels/Berlin.

Arora A. and A. Gambardella (1994), 'Evaluating Technological Information and Utilizing It - Scientific Knowledge, Technological Capability, and External Linkages in Biotechnology', Journal of Economic Behavior \& Organization, 24(1), 91-114.

Bayona, C., T. Garcia-Marco and E. Huerta (2001), 'Firms' motivations for cooperative R\&D: an empirical analysis of Spanish firms', Research Policy, 30(8), 1289-1307.

Berchicci L. (2013), 'Towards an open R\&D system: Internal R\&D investment, external knowledge acquisition and innovative performance', Research Policy, 42(1), 117127.

Bertrand, O. and M.J. Mol (2013), 'The Antecedents and Innovation Effects of Domestic and Offshore R\&D Outsourcing: The Contingent Impact of Cognitive Distance and Absorptive Capacity', Strategic Management Journal, 34(6), 751-760.

Boschma, R.A. (2005), 'Proximity and innovation: A critical assessment', Regional Studies, 39, 61-74.

Bottazzi, L. and G. Peri (2003), 'Innovation and spillovers in regions: Evidence from European patent data', European Economic Review, 47, 687-710.

Cassiman, B. and R. Veugelers (2006), 'In search of complementarity in innovation strategy: Internal R\&D and external knowledge acquisition', Management Science, 52, 68-82.

Chesbrough, H. (2003), Open Innovation: The new imperative for creating and profiting from technology. Harvard Business School Publishing: Boston, MA.

Christensen, T.A., G. Meier zu Köcker, T. Lämmer-Gamp, M. Solgaard Thomsen and K. Olesen (2011), Cluster and network policy programmes in Europe, Paper presented at the NGP Cluster Excellence conference, May 2011, Copenhagen.

Cohen, W.M. (1995), 'Empirical studies of innovative activities', In: Stoneman, P. (ed.), Handbook of the economics of innovation and technological change, Oxford: Basil Blackwell, 182-264.

Cohen, W.M. and D.A. Levinthal (1989), 'Innovation and learning: the two faces of R\&D’, The Economic Journal, 99(397), 569-596.

Cohen, W.M. and D.A. Levinthal (1990), 'Absorptive Capacity: A New Perspective on Learning and Innovation', Administrative Science Quarterly, 35, 128-152.

Cooke, P., M.G. Uranga and G. Etxebarria (1997), 'Regional Innovation Systems: Institutional and Organisational Dimensions', Research Policy, 26(4), 475-491.

de Jong, J.P.J. and M. Freel (2010), 'Absorptive capacity and the reach of collaboration in high technology small firms', Research Policy, 39(1), 47-54.

DiMaggio, P.J. and W.W. Powell (1983), 'The iron cage revisited: institutional 
isomorphism and collective rationality in organizational fields', American Sociological Review, 48(2), 147-160.

Drejer, I. and A. Vinding (2007), 'Searching Near and Far: Determinants of Innovative Firms' Propensity to Collaborate Across Geographical Distance', Industry and Innovation, 14, 259-275.

EIRMA (2004), Technology Access for Open Innovation, Report WG63. EIRMA: Paris. Eisenhardt, K.M., C.B. Schoonhoven (1996), 'Resource-Based View of Strategic Alliance Formation: Strategic and Social Effects in Entrepreneurial Firms', Organization Science, 7(2), 136-150.

Eisingerich, A.B., S.J. Bell and P. Tracey (2010), 'How can clusters sustain performance? The role of network strength, network openness, and environmental uncertainty', Research Policy, 39(2), 239-253.

Escribano, A., A. Fosfuri, A. and J.A. Tribo (2009), 'Managing external knowledge flows: The moderating role of absorptive capacity', Research Policy, 38, 96-105.

Freel, M. (2003), 'Sectoral patterns of small firm innovation, networking and proximity', Research policy, 32(5), 751-770.

Fukugawa, N. (2006), 'Determining factors in innovation of small firm networks: a case of cross industry groups in Japan', Small Business Economics, 27, 181-193.

Granovetter, M. (1983), 'The Strength of Weak Ties: A Network Theory Revisited', Sociological Theory, 1(1), 201-233.

Greunz, L. (2005), 'Intra- and inter-regional knowledge spillovers: evidence from European regions' European Planning Studies, 13, 449-473.

Grotz, R. and B. Braun (1997), 'Territorial or trans-territorial networking: spatial aspects of technology-oriented cooperation within the German mechanical engineering industry', Regional Studies, 31(6), 545-557.

Hagedoorn, J. and M. Cloodt (2003), 'Measuring innovative performance: is there an advantage in using multiple indicators?', Research Policy, 32, 1365-1379.

Hautala, J. (2011), 'Cognitive proximity in international research groups', Journal of Knowledge Management, 15, 601-624.

Herrmann, A.M., J.L. Taks and I. Moors (2012), 'Beyond regional clusters: on the importance of geographical proximity for R\&D collaborations in a global economy the case of the Flemish biotech sector', Industry and Innovation, 19(6), 499-516.

Hoekman, J., K. Frenken and R.J.W. Tijssen (2010), 'Research collaboration at a distance: Changing spatial patterns of scientific collaboration within Europe', Research Policy, 37, 662-673.

Howells, J. (1999), 'Regional systems of innovation?', In: Archibugi, D., J. Howells and J. Michie (eds.), Innovation Policy in a Global Economy. CUP: Cambridge, 67-93.

Huggins, R. and A. Johnston (2010), 'Knowledge flow and inter-firm networks: The influence of network resources, spatial proximity and firm size', Entrepreneurship \& Regional Development, 22(5), 457-484.

Jaffe, A.B., M. Trajtenberg and R. Henderson (1993), 'Geographic localization of knowledge spillovers as evidenced by patent citations', Quarterly Journal of Economics, 108(3), 577-598.

Johansson, D., D. Cetindamar, B. Carlsson and P. Braunerhjelm (2000), 'The old and the new: the evolution of polymer and biomedical clusters in Ohio and Sweden, Journal of Evolutionary Economics, 10(5), 471-488. 
Kogut, B. and U. Zander (1992), 'Knowledge of the firm, combinative capabilities, and the replication of technology', Organization Science, 3(3), 383-397.

Lam, A. (2006), 'Organizational Innovation', in: Fagerberg, J., D. Mowery and R.R. Nelson (eds), The Oxford Handbook of Innovation, Oxford University Press, chapter 5.

Lane, P.J., B.R. Koka and S. Pathak (2006), 'The Reification of Absorptive Capacity: A Critical Review and Rejuvenation of the Construct', Academy of Management Review, 31(4), 833-863.

Laursen, K. and A. Salter (2006), 'Open for innovation: The role of openness in explaining innovation performance among UK manufacturing firms', Strategic Management Journal, 27, 131-150.

Leonard, D. and S. Straus (1997), 'Putting Your Company's Whole Brain to Work', Harvard Business Review, 75, 110-122.

Malmberg, A. and P. Maskell (2002) The elusive concept of localization economies: towards a knowledge-based theory of spatial clustering, Environment and Planning A, 34, 429-449.

Maskell, P. (2001) Towards a knowledge-based theory of the geographical cluster, Industrial and Corporate Change, 10(4), 921-943.

Maskell, P. and A. Malmberg (2007) Myopia, knowledge development and cluster evolution, Journal of Economic Geography, 7, 603-618.

Mezias, J., P. Grinyer and W.D. Guth (2001), 'Changing Collective Cognition: A Process Model for Strategic Change', Long Range Planning 34(1), 71-95.

Miotti, L. and F. Sachwald (2003), 'Co-operative R\&D: why and with whom? An integrated framework of analysis', Research Policy, 32(8), 1481-1499.

Moodysson, J. and O. Jonsson (2007), 'Knowledge collaboration and proximity: the spatial organisation of biotech innovation projects', European Urban and Regional Studies, 14, 115-131.

Muscio, A. (2007), 'The impact of absorptive capacity on SME's collaboration', Economics of Innovation and New Technology, 16, 653-668.

Nieto, M.J., and L. Santamaria (2007), 'The importance of diverse collaborative networks for the novelty of product innovation', Technovation, 27, 367-377.

Nooteboom, B. (1994), 'Innovation and diffusion in small firms: theory and evidence', Small Business Economics, 6(5), 327-347.

Nooteboom, B., W. Vanhaverbeke, G. Duysters, V. Gilsing, and A. van den Oord (2007), 'Optimal Cognitive Distance and Absorptive Capacity', Research Policy, 36(7), 1016-1034.

OECD (2002), Frascati Manual: Proposed standard practice for surveys on research and experimental development. OECD: Paris.

OECD (2008), Open Innovation in Global Networks. OECD: Paris.

OECD/Eurostat (2005), Oslo Manual: Guidelines for collecting and interpreting innovation data, 3rd edition, OECD: Paris.

Oerlemans, L., M. Meeus and F. Boekema (1998), 'Do networks matter for innovation? The usefulness of the economic networks approach in analysing innovation', Tijdschrift voor Economische en Sociale Geografie, 89(3), 298-309.

Oxford Research (2008), Cluster policy in Europe, The Oxford Group: Kristiansand, Norway. 
Ponds, R., F. van Oort and K. Frenken (2010), 'Innovation, spillovers and universityindustry collaboration: An extended knowledge production function approach', Journal of Economic Geography, 10, 231-255.

Rodan, S. and C. Galunic (2004), 'More than Network Structure: How Knowledge Heterogeneity Influences Managerial Performance and Innovativeness', Strategic Management Journal, 25(6), 541-562.

Rosenkopf, L. and A. Nerkar (2001), 'Beyond local search: boundary-spanning, exploration, and impact in the optical disk industry', Strategic Management Journal, 22(4), 287-306.

Rosenkopf, L. and P. Almeida (2003), 'Overcoming local search through alliances and mobility', Management Science, 49, 751-766.

Rothaermel, F.T. and M.T. Alexandre (2009), 'Ambidexterity in Technology Sourcing: The Moderating Role of Absorptive Capacity', Organization Science, 20, 759-780.

Saxenian, A. (1994), Regional advantage: Culture and Competition in Silicon Valley and Route 128, Harvard University Press: Cambridge, MA.

Singh, J. (2005), 'Collaborative networks as determinants of knowledge diffusion patterns', Management Science, 51(5), 756-770.

Sole, D. and A. Edmondson (2002), 'Situated Knowledge and Learning in Dispersed Teams', British Journal of Management, 13, S17-S34.

Sorenson, O., J.W. Rivkin and L.Fleming (2006), 'Complexity, networks and knowledge flow', Research Policy, 35(7), 994-1017.

Tallman, S. and A. Phene (2007), 'Leveraging knowledge across geographical boundaries', Organization Science, 18(2), 252-260.

Tödtling, F., P. Lehner and M. Trippl (2006), 'Innovation in knowledge intensive industries: The nature and geography of knowledge links', European Planning Studies, 14(8), 1035-1058.

Tomlinson, P.R. (2010), Co-operative ties and innovation: Some new evidence for UK manufacturing', Research Policy, 39(6), 762-775.

Tsai, K.H. (2009), 'Collaborative networks and product innovation performance: Toward a contingency perspective', Research Policy, 38(5), 765-778.

Tsipouri, L., A. Reid and M. Miedzinski (2008), European Innovation progress report. European Commission DG Enterprise and Industry: Brussels.

van der Vrande, V., J.P.J. de Jong, W. Vanhaverbeke and M. de Rochemont (2009), 'Open Innovation in SMEs: Trends, Motives and Management Challenges', Technovation, 29(6-7), 423-437.

Zahra, S.A. and G. George (2002), Absorptive Capacity: A Review, Reconceptualization, and Extension, Academy of Management Review, 27(2), 185-203. 
Table 1. Descriptive statistics $(n=248)$

\begin{tabular}{|c|c|c|c|c|c|c|c|c|c|c|c|c|c|c|c|c|c|}
\hline & & Mean & SD & Min & $\operatorname{Max}$ & 1 & $\frac{1}{2}$ & 3 & 4 & 5 & 6 & 7 & 8 & 9 & 10 & 11 & 12 \\
\hline 1 & $\begin{array}{l}\text { Log share of new product } \\
\text { revenues }\end{array}$ & 3.44 & 1.03 & 0 & 4.61 & & & & & & & & & & & & \\
\hline 2 & $\begin{array}{l}\text { Share of remote partners } \\
(>750 \mathrm{~km})\end{array}$ & 0.1 & 0.19 & 0 & 1 & $0.17 * *$ & & & & & & & & & & & \\
\hline 3 & R\&D intensity & 0.25 & 0.25 & 0.03 & 1 & $0.26^{* * *}$ & 0.12 & & & & & & & & & & \\
\hline 4 & Collaboration volume & 4.68 & 2.42 & 1 & 14 & 0.10 & $0.13 *$ & $0.17 * *$ & & & & & & & & & \\
\hline 5 & Log firm size & 2.43 & 0.82 & 0.69 & 4.61 & $-0.39 * * *$ & -0.08 & $-0.36 * * *$ & 0.08 & & & & & & & & \\
\hline 6 & Log firm age & 2.44 & 1.08 & 0.69 & 4.91 & $-0.28 * * *$ & -0.06 & $-0.37 * * *$ & 0.10 & $0.63^{* * *}$ & & & & & & & \\
\hline 7 & Innovation ambition & 0.67 & 0.47 & 0 & 1 & -0.03 & 0.04 & 0.11 & $0.13 *$ & 0.00 & $0.12 *$ & & & & & & \\
\hline 8 & ICT & 0.33 & 0.47 & 0 & 1 & $0.19 * *$ & -0.10 & 0.05 & $-0.16^{*}$ & $-0.20 * *$ & -0.06 & -0.08 & & & & & \\
\hline 9 & Machinery/production & 0.2 & 0.4 & 0 & 1 & -0.00 & $-0.13 *$ & -0.07 & -0.08 & 0.09 & 0.04 & -0.02 & $-0.32 * * *$ & & & & \\
\hline 10 & Bio/food & 0.13 & 0.34 & 0 & 1 & 0.00 & 0.08 & $0.21 * * *$ & 0.11 & 0.04 & 0.05 & 0.12 & $-0.27 * * *$ & $-0.16^{*}$ & & & \\
\hline 11 & Chemical & 0.1 & 0.3 & 0 & 1 & -0.00 & $0.15 *$ & 0.09 & $0.15 *$ & 0.11 & 0.09 & $0.14 *$ & $-0.20 * *$ & $-0.13 *$ & 0.037 & & \\
\hline 12 & Energy & 0.13 & 0.33 & 0 & 1 & -0.09 & 0.03 & 0.02 & $0.21 * * *$ & -0.04 & -0.08 & 0.08 & $-0.21 * * *$ & $-0.13 *$ & -0.07 & -0.08 & \\
\hline 13 & Construction & 0.02 & 0.15 & 0 & 1 & -0.06 & 0.01 & -0.09 & -0.03 & 0.09 & 0.06 & -0.05 & -0.05 & -0.08 & -0.06 & -0.051 & -0.06 \\
\hline
\end{tabular}


Table 2. Tobit regression models of new product revenue share $(n=248)$

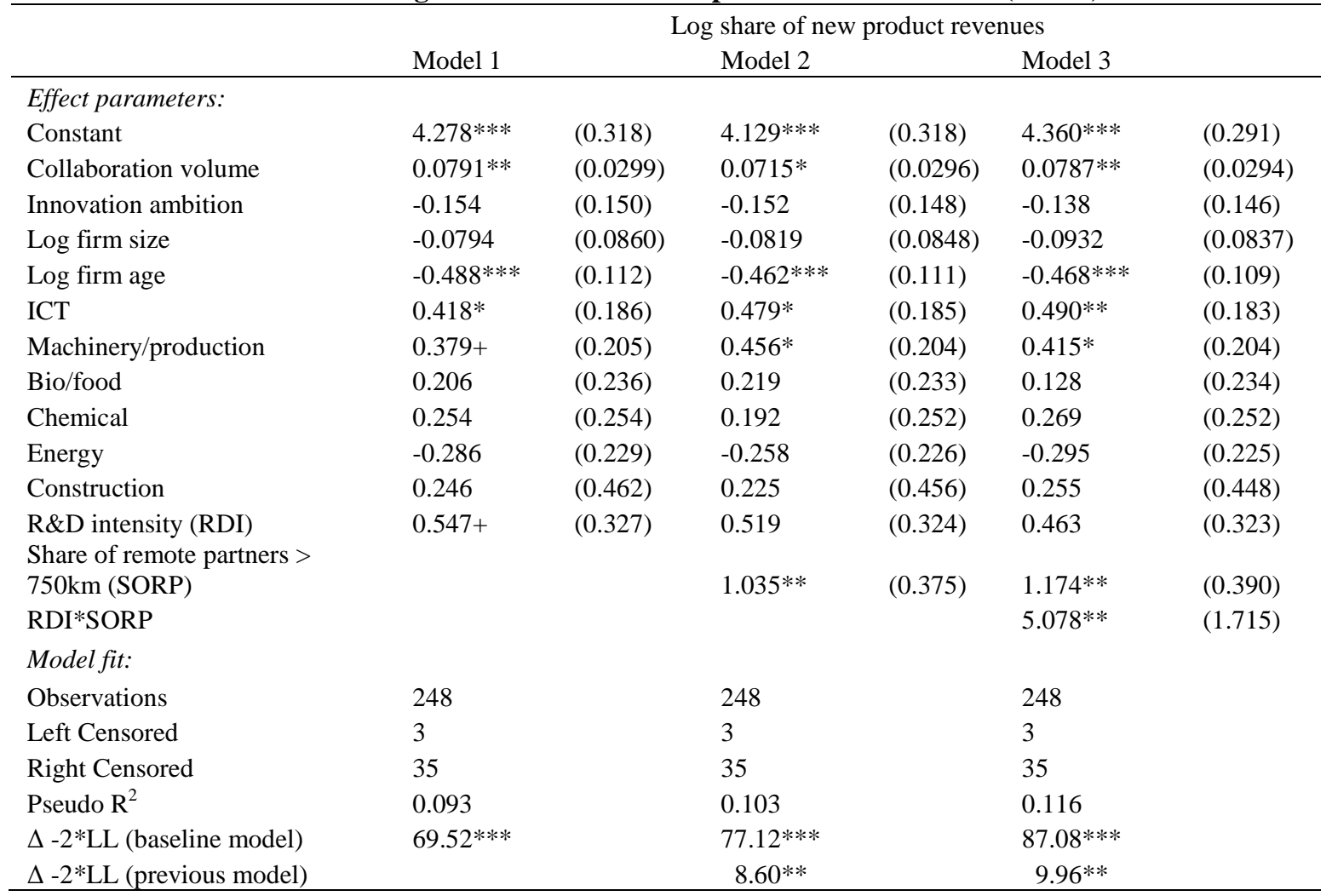

Notes: Standard errors in parentheses. $+\mathrm{p}<0.10 * \mathrm{p}<0.05 * * \mathrm{p}<0.01 * * * \mathrm{p}<0.001$. 
Figure 1. Simple tobit regression models of the share of new product revenues $(n=248)$

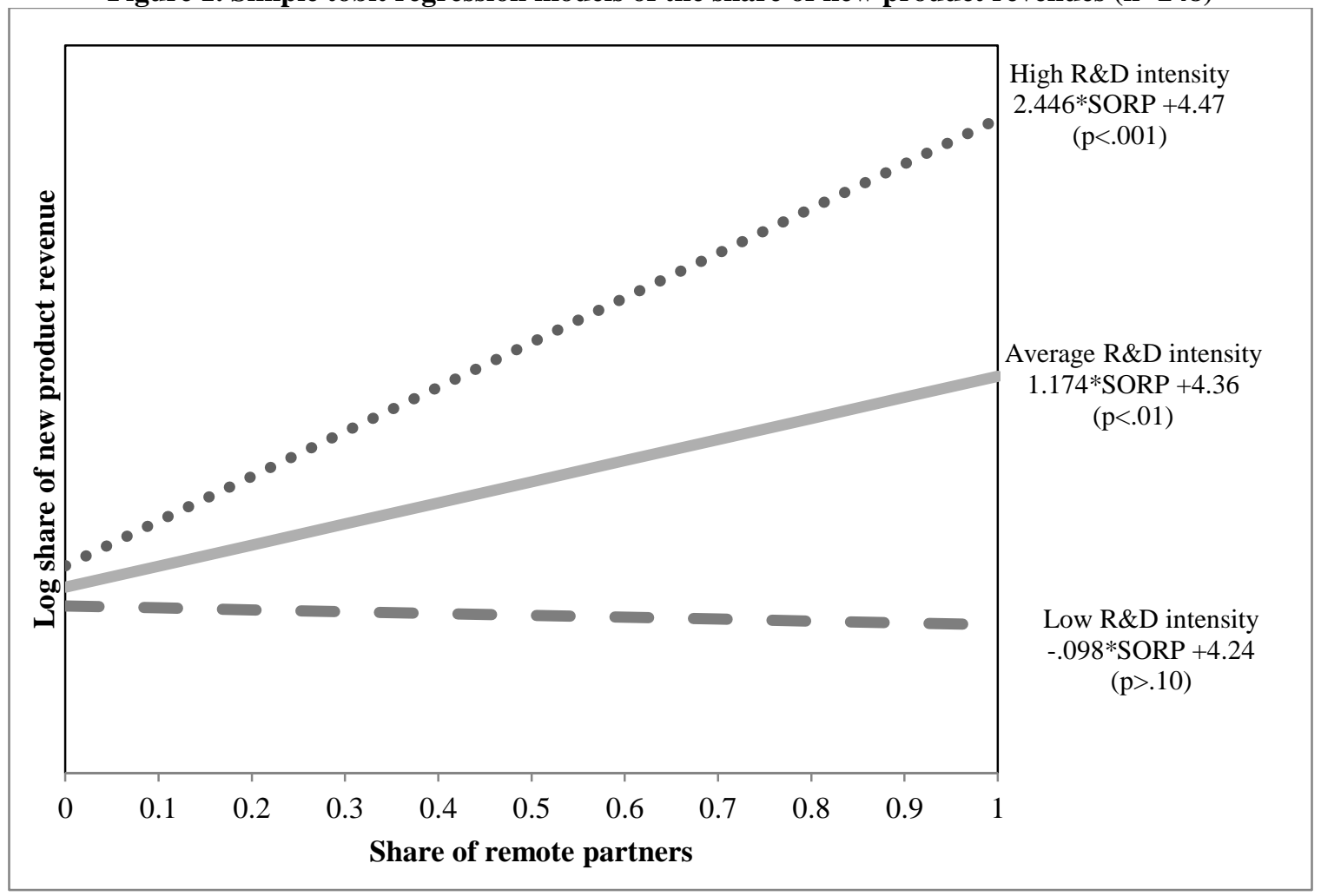


Table 3. Estimation models for instrumental variables

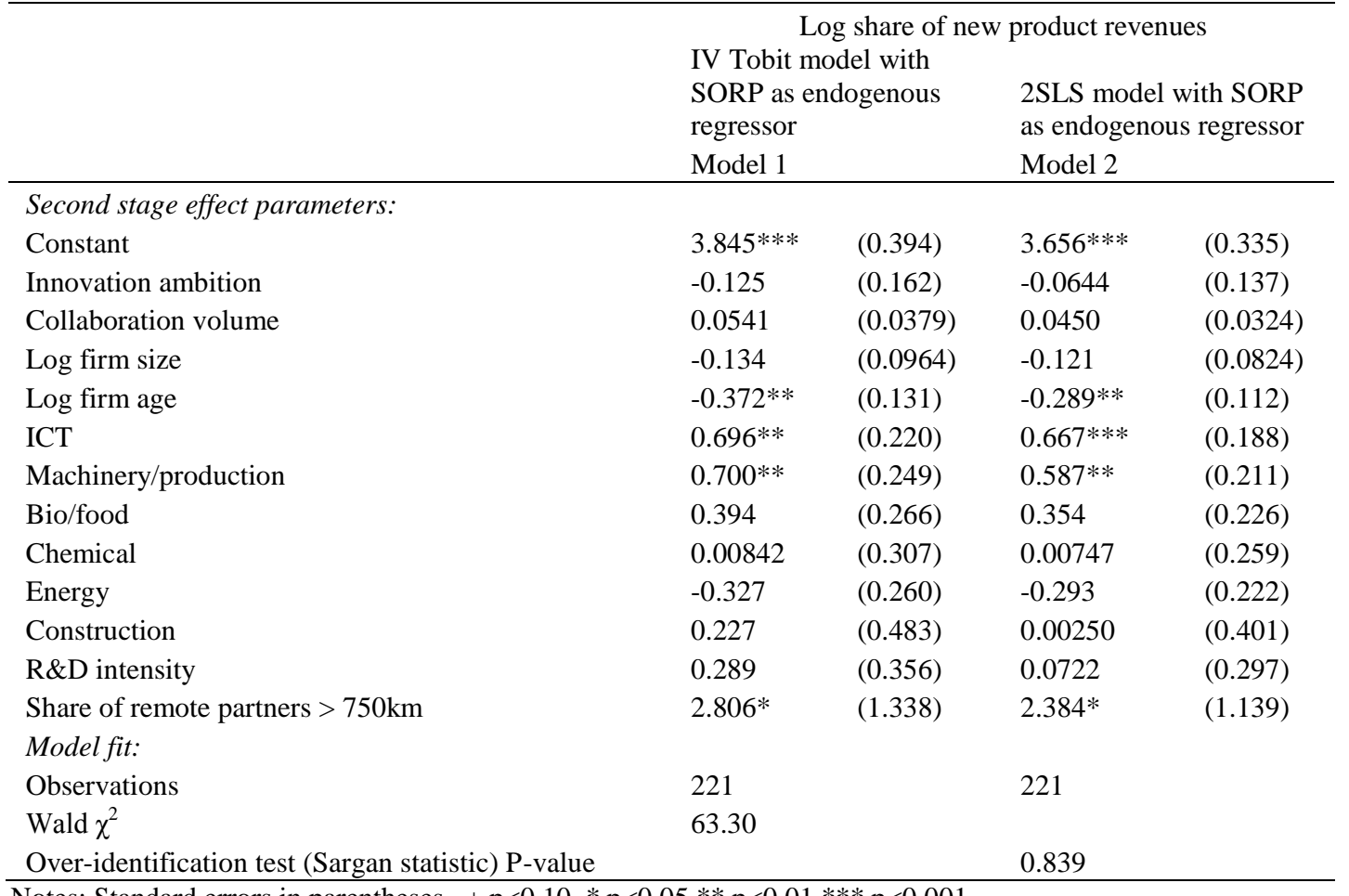

Notes: Standard errors in parentheses. $+\mathrm{p}<0.10 * \mathrm{p}<0.05 * * \mathrm{p}<0.01 * * * \mathrm{p}<0.001$. 